ERRATA

in Entomophaga, 4 (3), 1959

\title{
ZUR ISOLIERUNG UND KULTUR INSEKTENPATHOGENER ENTOMOPHTHORACEEN
}

VON

E. MülleR-Kögler (*)

S. 271, 9. und 10. Zeile von oben muss es heissen :...Milch-Agar, MilchHafermehl-Agar und Fleischextrakt-Pepton-Dotter-Agar...

S. 273 : MacLeod statt McLeod.

S. 262 : Anmerkung zu Zeile 4-6 von oben : Während die Arbeit im Druck war, veröffentlichten HaLL und HaLfHILL (J.econ. Ent., 52, 30-35, 1959) ihre Versuche mit Dauersporen von Entomophthora virulenta HALL ET DUNN. Danach können diese sofort zu 2-5\% innerhalb 4 Tagen auf Nährböden auskeimen. Durch chitinspaltende Bakterien wurde ihre Keimung nicht beeinflusst.

S. 270 : Anmerkung zu Zeile 20 von oben : HaLl und HaLfHrLl (s. vorstehende Anm.) konnten inzwischen feststellen, dass man ausgehend von bakterienverunreinigten Dauersporen von Entomophthora virulenta HALL ET DUNN saubere Pilzkolonien erhalten kann auf einem Pepton-Glucose-Agar mit Bengalrosa und Streptomycin oder auf SabouraudGlucose-Agar mit Streptomycin.

S. 272 : Anmerkung zu Summary : Herrn Dr. J. D. BrIgGs, Wasco/ Kalifornien, danke ich sehr für kritische Durchsicht der engl. Zusammenfassung.

(*) Le secrétariat de la Revue présente ses excuses à l'auteur pour les omissions qui se sont produites lors de l'impression et de la correction de cet article. 